\title{
Effect of pH on Optic and Structural Characterization of Chemical Deposited AgI Thin Films
}

\author{
Fatma Meydaneri Tezel ${ }^{a}$, İshak Afşsin Kariper ${ }^{b}$ \\ ${ }^{a}$ Department of Metallurgy and Materials Engineering, Faculty of Engineering, Karabük \\ University, 78050, Karabük, Turkey \\ ${ }^{b}$ Department of Science Education, Faculty of Education, Erciyes University, 38039, Kayseri, Turkey
}

Received: March 26, 2017; Revised: May 29, 2017; Accepted: June 20, 2017

\begin{abstract}
AgI thin films were grown on amorphous commercial glass substrates with chemical bath deposition (CBD) at different $\mathrm{pH}$ values $(2,3,4,5,6), 6$ hours deposition time and $60{ }^{\circ} \mathrm{C}$. The structure of the nanocrystals was characterized by X-ray diffraction (XRD). The ratio of $\mathrm{Ag}^{+}$and $\mathrm{I}^{-}$ions changed the crystalline structures. The presence of the $\mathrm{Ag}^{+}$ions produces the $\gamma$-phase of $\mathrm{AgI}$ and excess of iodine concentration produces $\beta$-phase of AgI. The $\mathrm{pH}$ : 4 was like a transition $\mathrm{pH}$ for these phases. The number of crystallites per unit area has maximum value at $\mathrm{pH}$ : 5 , as the structure is re-crystallization to hexagonal phase. Also, the thicknesses of produced thin films were decreased with increased $\mathrm{pH}$ values. Therefore, transmission, reflection, extinction coefficients and refractive index of the materials were affected by thicknesses, and calculated to be $32,35,3,11,9(\%)-27,25,61,45,49$ (\%) - 0.036, 0.032, 0.067, 0.107, 0.075 and 3.21, 3.02, 5.16, 8.35, 5.70 in $550 \mathrm{~nm}$ at pH: 2-3-4-5-6 values, respectively. The exciton peaks of AgI were observed at between 320 and $420 \mathrm{~nm}$. Surface properties were investigated by using scanning electron microscopy (SEM).
\end{abstract}

Keywords: AgI, crystal growth, pH effect, chemical bath deposition, optical and surface properties.

\section{Introduction}

Semiconductor industry has significantly developed and will develop next years. The chalcogenides are very useful in the semiconductor industry, for instance, they are used in computers. These materials are used in two terminal devices which have two different resistance states ${ }^{1,2}$. This situation was investigated widely in the optoelectronic world. AgI synthetic particles were also known as well semiconductors due to their photosensitivity and superionic conductivity ${ }^{3-7}$. The crystallite size and crystal structure of AgI have been affected by growth mechanism which is important in terms of photosensitivity. Therefore, we have to give much attention to characterization and preparation of $\mathrm{AgI}^{8-16}$.

According to the literature, it has been observed several polymorphic forms depending on the experimental conditions and the temperature of formation ${ }^{17}$. AgI occurred in two polymorphic forms; a hexagonal wurtzite type $\beta$-AgI structure and cubic zinc blend type $\gamma$-AgI structure. Moreover, AgI changed several phases from cubic $\gamma$ phase to the rhombohedral, tetragonal and rock salt modifications with magnitude of pressure, also ZnS-type structural system is observed ${ }^{18,19}$.

Many researchers attempted to produce AgI films according to these different properties of AgI. Someone investigated $\gamma$-AgI formation, its' memory effect and someone searched its' structural and morphological properties. The resistance switching of AgI was obtained to control the current or the voltage of the devices. This property and the other properties of AgI depend on its structure and electrical properties. For instance, the resistivity of AgI was $1 \Omega \mathrm{cm}$ at $200{ }^{\circ} \mathrm{C}$ for $\alpha$-AgI structure, but $\mathrm{AgI}$ had $\beta$ and $\alpha$ phase at $147^{\circ} \mathrm{C}$. So, the structure of AgI crystal changes depending on preparation conditions.

The research related to the effects of $\mathrm{pH}$ with chemical bath on AgI structure and optical properties for the solar cell substrates can be rarely found in literature. Therefore, in this study, our purpose is to investigate the effects of $\mathrm{pH}$ and doping parameters on AgI thin films growth with CBD. The characterizations of the surface, structural, optical properties depending on crystal growth were examined.

\section{Experimental Procedure}

\subsection{Crystal growth and characterizations}

All chemicals were purchased from Merck and Aldrich and they were used without further purification. High purity reagents were used in preparing all of the solutions. The stock solutions with several concentrations were diluted daily in order to be used as solutions. The other stock solutions were prepared from highly pure compounds $(99.9 \%$, E. Merck, Darmstadt, Sigma Aldrich). All plastic and glassware 
equipment were cleaned by soaking them in dilute $\mathrm{HNO}_{3}$ and were rinsed with deionizer water before they were used. Substrates were cleaned and dipped into alcohol and $\mathrm{HNO}_{3}$. Baths with concentrations $\mathrm{AgCl}, 1 \times 10^{-3} \mathrm{M}$; KI $1 \times 10^{-3} \mathrm{M}$; $\mathrm{HNO}_{3} 0.1 \mathrm{M}$, were used. In order to adjust the $\mathrm{pH}$ value of the solution as $2,3,4 ; 1100 \mu 1,80 \mu 1,8 \mu \mathrm{l}$ of nitric acid $\left(\mathrm{HNO}_{3}\right)$, respectively, and $14 \mu \mathrm{L} 0.1 \mathrm{M} \mathrm{KOH}$ solution for $\mathrm{pH}$ : 6. But, nothing was added to the solution of $\mathrm{pH}$ : 5 . The $\mathrm{pH}$ meter was used to measure the $\mathrm{pH}$ values of the chemical baths (Lenko mark 6230N). The samples were left in the oven at $60^{\circ} \mathrm{C}$ for 6 hours.

The chemical reactions for the deposition of the silver iodide crystals taking place on the glass substrate in the bath are as below. Silver ions $\left(\mathrm{Ag}^{+}\right)$don't dissolve with iodine $\left(\mathrm{I}^{-}\right)$in the bath and form an insoluble AgI.

$$
\begin{gathered}
\mathrm{H}_{3} \mathrm{O}^{+}{ }_{(\mathrm{aq})}+\mathrm{I}_{(\mathrm{aq})}^{-} \longleftrightarrow \mathrm{H}_{2} \mathrm{O}+\mathrm{HI}_{(\mathrm{aq})} \\
\mathrm{Ag}_{(\mathrm{aq})}^{+}+\mathrm{I}^{-}{ }_{(\mathrm{aq})} \longrightarrow \mathrm{AgI}_{(\mathrm{k})}
\end{gathered}
$$

Silver nitrate and potassium iodide were used for formation of AgI (2), but the chemical bath was in acidic area at pH: 2-6 (1). Hydrogen iodide occurred in reaction. When the $\mathrm{pH}$ of bath is decreased by adding nitric acid, iodine concentration decreases. So, the formation AgI depended on $\mathrm{HI}$ (1) reaction and $\mathrm{pH}$ of the bath. The $\mathrm{pH}$ of the bath affected the film thickness grown on glass substrate and structure of AgI crystals.

The crystalline structure of AgI was determined by X-ray diffraction (XRD) with a $\mathrm{CuK} \alpha_{1}$ radiation source (Rikagu RadB model, $\lambda=1.5406 \AA$ ) over the range $10^{\circ}<2 \theta<90^{\circ}$ at a speed of $3^{\circ} \mathrm{min}^{-1}$ with a step size of $0.02^{\circ}$. We investigated the surface properties of all of formed crystals by using an EVO40-LEO computer controlled digital scanning electron microscope (SEM). Ratio of chemical compositions was measured by an EDX spectrometer attached to the SEM. We used Lange 500 Spectrophotometer at room temperature to make optical measurements by placing an uncoated identical glass substrate in the reference beam. The optical spectrum of the thin films grown on glass substrate was recorded in the wavelength at the range of 200-1100 nm. The thicknesses of the thin films were measured with a Veeco Multi Mode AFM (Controller=NanoScope 3D).

\section{Results and Discussion}

\subsection{Structural properties}

It was seen that XRD patterns changed with $\mathrm{pH}$ of the chemical bath. The peaks of $\gamma$-AgI and $\beta$-AgI can be observed at the diffraction angle of $10^{\circ}<2 \theta<90^{\circ}$ on the XRD spectrum. These diffraction patterns have cubic $(\gamma-\mathrm{AgI})$ and hexagonal $(\beta-\mathrm{AgI})$ structures and preferential orientation in the (111), (220) and (311) plane at $\mathrm{pH}: 2,(220),(111)$, (101) and (112) at pH: 3, (220), (111), (101), (110), (220), (103) and (112) at pH: 4, (002), (102), (110) and (112) at pH: 5, (002), (102), (110) and (112) at pH: 6. The intensity of XRD peaks, preferential orientation of atoms and crystal structures changed with deposition $\mathrm{pH}$, were shown in Fig. 1 and Table 1. According to Kennedy ${ }^{17}$, Ves and et. al ${ }^{18}$ and Goswami ${ }^{19}, \gamma$ - and $\beta$-AgI phase depends on the high temperature, not only the temperature but also $\mathrm{pH}$ changed the phase in this study. The $\mathrm{pH}$ of bath directly affected the iodine concentration, and the iodine concentration decreased below $\mathrm{pH}: 5-6$. While $\gamma$-AgI phase was observed at the lower $\mathrm{pH}(\mathrm{pH}=2-4)$, iodine concentration increased above $\mathrm{pH}$ : 5-6 and $\gamma$-AgI phase is transformed to $\beta$-AgI phase depend on XRD spectrum. The XRD patterns showed that iodized Ag film contained $\beta$-phase of AgI which was confirmed by the (102) and (103) peaks when XRD data of $\gamma$-AgI determined superposition with the (002) and (112) peaks by Liang ${ }^{20}$, Kumar $^{21}$ and Validźićc 22.

Crystal lattice parameters along the (111) at $\mathrm{pH}: 2,(300)$ at $\mathrm{pH}: 3,(300)$ at $\mathrm{pH}: 4,(001)$ at $\mathrm{pH}: 5$ and (001) at $\mathrm{pH}: 6$ plane were calculated by using the formulas given below,

$$
d^{2}=\frac{a^{2}}{h^{2}+k^{2}+l^{2}} \quad(\text { Cubic Structure })
$$

$$
\frac{1}{d^{2}}=\frac{4}{3}\left(\frac{h^{2}+h k+k^{2}}{a^{2}}\right)+\frac{l^{2}}{c^{2}} \quad \text { (Hexagonal Structure) }
$$

crystallite size (D), dislocation density $(\delta)$ and the number of crystallization per unit area $(\mathrm{N})$ were obtained by using Scherrer's formula ${ }^{23-25}$ :

$$
\begin{gathered}
D=\frac{0.9 \lambda}{\beta \cos \theta} \\
\delta=\frac{1}{D^{2}} \\
N=\frac{t}{D^{3}}
\end{gathered}
$$

where $t$ is the formed crystal layer thickness, $\lambda$ is wavelength of X-ray (1.5406 $\AA$ ), $\beta$ is FWHM of the peak, $\theta$ is Bragg's angle, $\delta$ is dislocation density which is defined as the length of dislocation lines per unit volume of the crystal. Higher $\delta$ values indicate lower crystalline levels and the amount defects in the structure. In this study, a higher $\delta$ value was calculated at $\mathrm{pH}: 4$, since the cubic structure of AgI converted to hexagonal phase. So, the $\mathrm{pH}$ : 4 was like a transition $\mathrm{pH}$ for these phases. The number of crystallites per unit area has maximum value at $\mathrm{pH}$ : 5, as the structure is re-crystallization to hexagonal phase. The crystallites obtained at pH: 2-4-6 had the best crystallinity. The changes in dislocation density, the number of crystallites per unit area and the average crystallite sizes are presented in Fig. 2. 


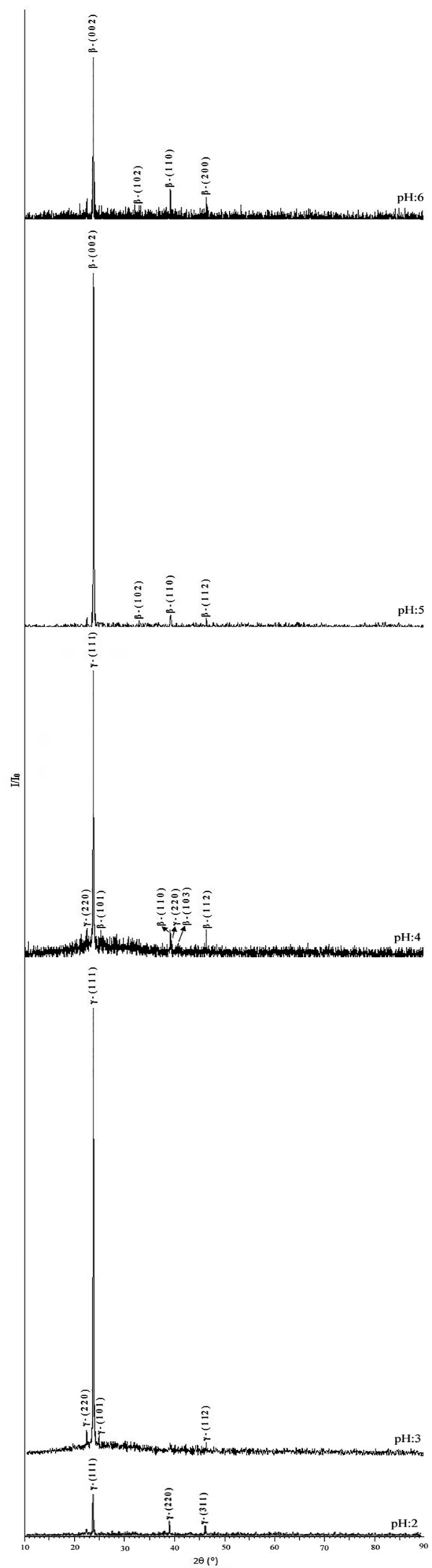

Figure 1. XRD spectrum of AgI thin films (a) $\mathrm{pH}: 2$, (b) pH: 3, (c) pH: 4, (d) pH: 5, (e) pH: 6.

\subsection{Concentration distribution and surface morphology}

Energy-dispersive X-ray analysis (EDX) was used in order to understand the effect of the ion concentrations on the structure. Theoretically, the $\mathrm{Ag}^{+}$and $\mathrm{I}^{-}$ions are $45.94 \%$, $54.06 \%$ and atomic ratio is $(\mathrm{Ag} / \mathrm{I}) 0.84979$ respectively. As seen in Fig. 3, the ratio of $\mathrm{Ag}^{+}$and $\mathrm{I}^{-}$ions decrease with increasing $\mathrm{pH}$ values. The presence of $\mathrm{Ag}^{+}$ions gets the $\gamma$-phase of AgI and excess of iodine concentration produces $\beta$-phase of AgI. The iodine concentration increases at $\mathrm{pH}: 5$ and 6, and the structure transforms from $\gamma$-phase to $\beta$-phase, and $\gamma$-phase observes at $\mathrm{pH}$ : 2-4. The atomic ratio is about 0.83 at $\mathrm{pH}$ : 6 . The hexagonal wurtzite type ( $\beta$-AgI) is observed while the silver and iodine atomic ratio is below 0.90 . The cubic zinc blend type $(\gamma-\mathrm{AgI})$ forms while the atomic ratio of silver and iodine is over 0.90 .

The SEM images of the thin films with same magnification factor for $\mathrm{pH}: 2-6$ are depicted in Fig. 4. As seen from SEM images, the thin films are very dense except for $\mathrm{pH}: 2$. It is seen that crystallization is rare for $\mathrm{pH}: 2$, but any broke are not observed on the surface. As seen from figures, crystals bonded substrate. Small particles are obtained for $\mathrm{pH}: 2-4$ and both big and small particles are obtained for $\mathrm{pH}: 5$ and 6 . For each $\mathrm{pH}$ value, specific accumulate type of the crystals are observed for some regions. This is a result of preferred growth of atoms. This situation can be explained by speed of reaction in solution, amorphous structure of substrate, temperature difference of particles inside solution, $\mathrm{pH}$ value and composition of solution. Crystallization number for unit surface area and dislocation density are also fluctuating with the effect of the phase transitions.

\subsection{Optical properties}

The transmittance ( $\mathrm{T}$ ) for AgI thin films formed on glass substrates can be obtained by using absorbance (A) and reflectivity (R) spectra from the expression ${ }^{26}$ :

$$
T=(1-R)^{2} e^{-A}
$$

Transmission and the reflectivity measurements are performed at room temperature at the range of 200-1100 nm, and absorption and transmission-reflectivity curves versus wavelengths are shown in Figs. 5-6, respectively. The absorption coefficient, $\alpha$ determines effective penetration distance of light with a particular wavelength inside the material. As seen from Fig. 5, the absorption coefficients $(\alpha)$ are changed to be 0.497 , $0.447,1.478,0.935$ and 1.041 at $\mathrm{pH}: 2,3,4,5,6$ in the visible region $(550 \mathrm{~nm})$, respectively. Optical transmission was the largest at pH: 4; then the transmission values decreased at $\mathrm{pH}$ 5-6. The transmission and reflection values of AgI thin crystalline layers occurred on glass substrates are obtained to be $32,35,3,11,9 \%$ and $27,25,61,45,49 \%$ in $550 \mathrm{~nm}$ at $\mathrm{pH}: 2,3,4,5,6$ values, respectively. The exciton peaks 
Table 1. The observed and literature peaks (ASTM Data) and crystal orientations at the diffraction angle for the crystals grown at different $\mathrm{pH}$ values.

\begin{tabular}{|c|c|c|c|c|c|}
\hline $\mathrm{pH}$ value & $(\mathrm{h} \mathrm{k} \mathrm{l)}$ & $2 \theta$ (Observed) & $2 \theta$ (Calculated) & $\mathrm{I} / \mathrm{I}_{\mathrm{o}}$ & Structure \\
\hline \multirow{3}{*}{$\mathrm{pH}: 2$} & $\gamma-(111)$ & 23.675 & 23.694 & 100.0 & \multirow{7}{*}{ Cubic } \\
\hline & $\gamma-(220)$ & 39.142 & 39.175 & 28.2 & \\
\hline & $\gamma-(311)$ & 46.320 & 46.296 & 22.0 & \\
\hline \multirow{4}{*}{ pH: 3} & $\gamma-(220)$ & 22.340 & 22.335 & 6.1 & \\
\hline & $\gamma-(111)$ & 23.500 & 23.709 & 100.0 & \\
\hline & $\gamma-(101)$ & 24.709 & 24.600 & 5.2 & \\
\hline & $\gamma-(112)$ & 46.200 & 46.202 & 3.0 & \\
\hline \multirow{7}{*}{ pH: 4} & $\gamma-(220)$ & 22.340 & 22.360 & 3.3 & \multirow{7}{*}{ Cubic + Hexagonal } \\
\hline & $\gamma-(111)$ & 23.739 & 23.735 & 100.0 & \\
\hline & $\beta-(101)$ & 24.906 & 23.710 & 3.2 & \\
\hline & $\beta-(110)$ & 39.248 & 39.245 & 1.7 & \\
\hline & $\gamma-(220)$ & 39.250 & 39.245 & 1.5 & \\
\hline & $\beta-(103)$ & 40.700 & 42.630 & 0.9 & \\
\hline & $\beta-(112)$ & 46.000 & 45.570 & 0.7 & \\
\hline \multirow{4}{*}{ pH: 5} & $\beta-(002)$ & 23.701 & 23.723 & 100.0 & \multirow{8}{*}{ Hexagonal } \\
\hline & $\beta-(102)$ & 33.000 & 32.809 & 4.1 & \\
\hline & $\beta-(110)$ & 39.200 & 39.214 & 8.1 & \\
\hline & $\beta-(112)$ & 46.359 & 46.347 & 9.9 & \\
\hline \multirow{4}{*}{ pH: 6} & $\beta-(002)$ & 23.681 & 23.723 & 100.0 & \\
\hline & $\beta-(102)$ & 32.500 & 32.809 & 4.1 & \\
\hline & $\beta-(110)$ & 39.191 & 39.196 & 19.0 & \\
\hline & $\beta-(112)$ & 46.265 & 46.347 & 11.00 & \\
\hline
\end{tabular}

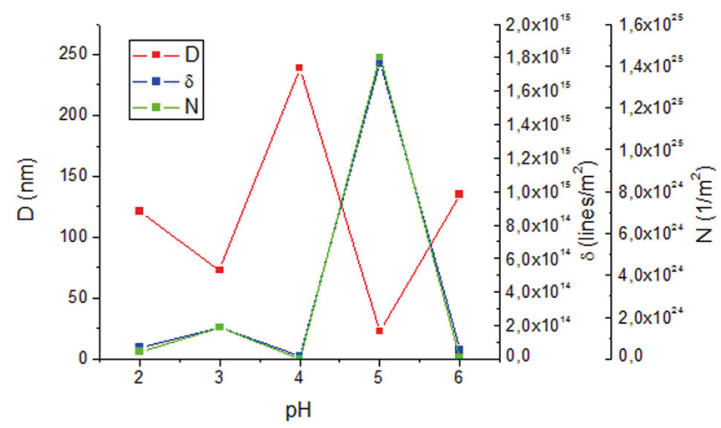

Figure 2. Variation of the dislocation density $(\delta)$, the number of crystalline (N) and the crystallite size (D) of the AgI thin films as a function of the $\mathrm{pH}$ of the chemical bath.

of $\mathrm{AgI}$ were observed at between 320 and $420 \mathrm{~nm}$ with $\mathrm{pH}$ : $2,3,4,5$ to be similar with the findings in literature, so the transmission and reflection curves are touching each other in these wavelengths ${ }^{4,27-29}$. In terms of optical properties; if you produced AgI thin crystalline layers with different solvents with spray pyrolysis technique, exciton peak of AgI was observed around $420 \mathrm{~nm}$ dispersion in water when 360-495 nm aged in 2-propanol. The preparation of AgI with different solvents affected absorption wavelength with spray pyrolysis technique ${ }^{20-22}$.

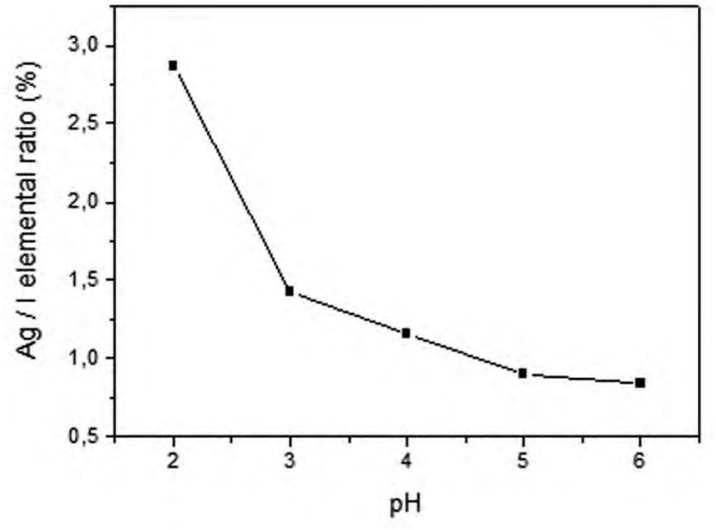

Figure 3. The ratio of $\mathrm{Ag}^{+}$and $\mathrm{I}^{-}$ions.

The refractive index and extinction coefficient for the materials are given as $^{26}$ :

$$
\begin{gathered}
n=\frac{1+R}{1-R}+\sqrt{\frac{4 R}{(1-R)^{2}}-k^{2}} \\
k=\frac{\alpha \lambda}{4 \pi}
\end{gathered}
$$



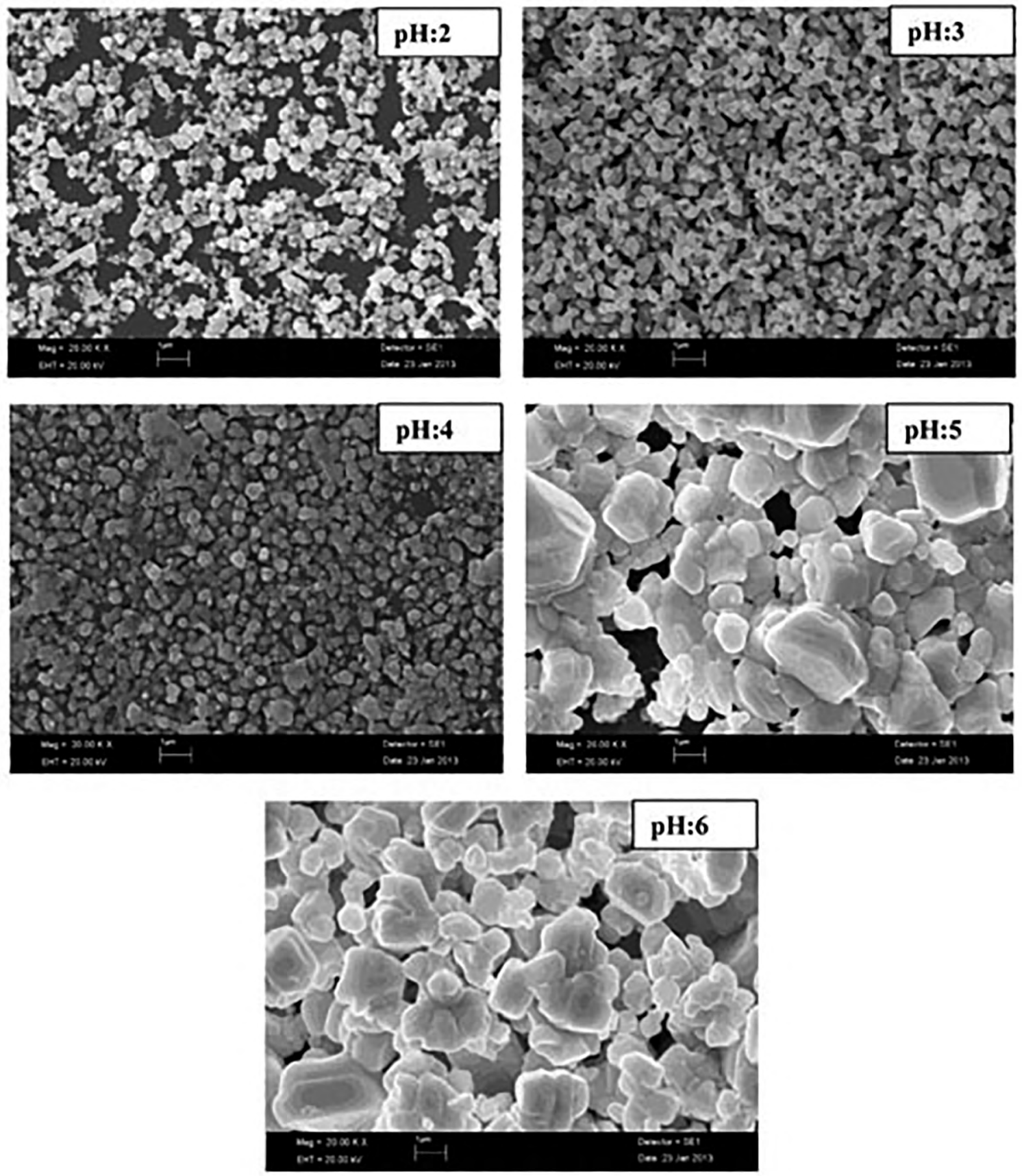

Figure 4. SEM imagines of AgI thin films.

The changes of the refractive indexes and extinction coefficients versus wavelength are shown in Fig. 7. The refractive index formed a shape similar to the reflection. The refractive indexes are changed to be $3.21,3.02,5.16$, 8.35 and 5.70 at $\mathrm{pH}: 2-6$, respectively. The refractive index has the highest at $\mathrm{pH}: 5$. The film thickness affected the refractive index and extinction coefficient. The thicknesses of the thin films are decreased with increased $\mathrm{pH}$ values as shown in Fig. 8.
The optical constants are parameters which define the reaction of a matter excited by an electromagnetic radiation at a given wavelength. These optical constants can be expressed as a complex dielectric function by the following formula ${ }^{30,31}$ :

$$
\varepsilon=\varepsilon_{1}+\mathrm{i} \varepsilon_{2}
$$

or as a complex refractive index by the following formula: 


$$
\mathrm{n}=\mathrm{n}_{\mathrm{r}}+\mathrm{ik}
$$

$$
\varepsilon_{1}=\mathrm{n}_{\mathrm{r}}^{2}-\mathrm{k}^{2}
$$

$$
\varepsilon_{2}=2 \mathrm{nk}
$$

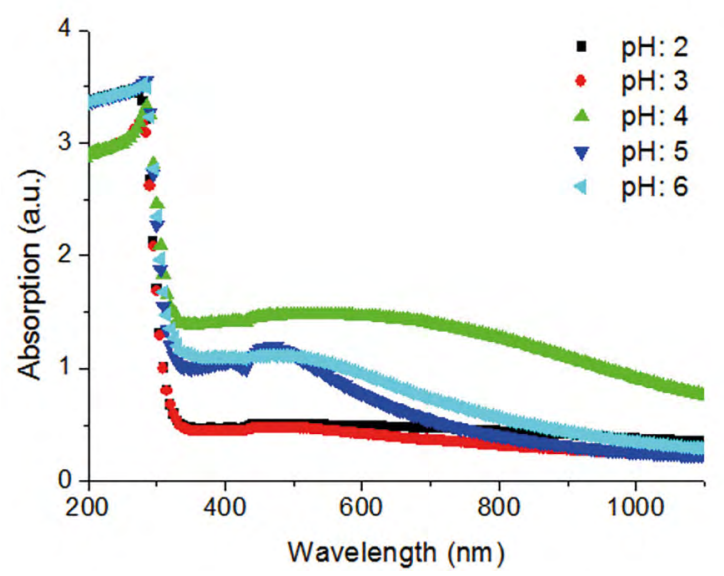

Figure 5. The absorbance change versus wavelength of AgI thin films grown at different $\mathrm{pH}$ values.

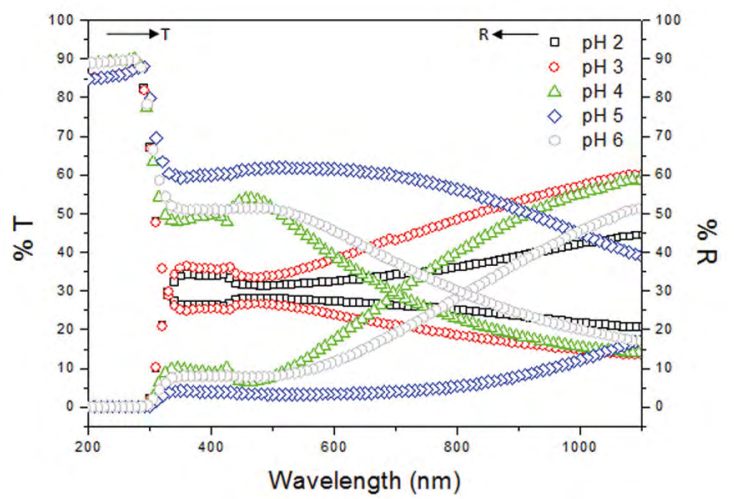

Figure 6. Optical transmission and reflectance spectra of AgI thin films grown at different $\mathrm{pH}$ values of the chemical bath.
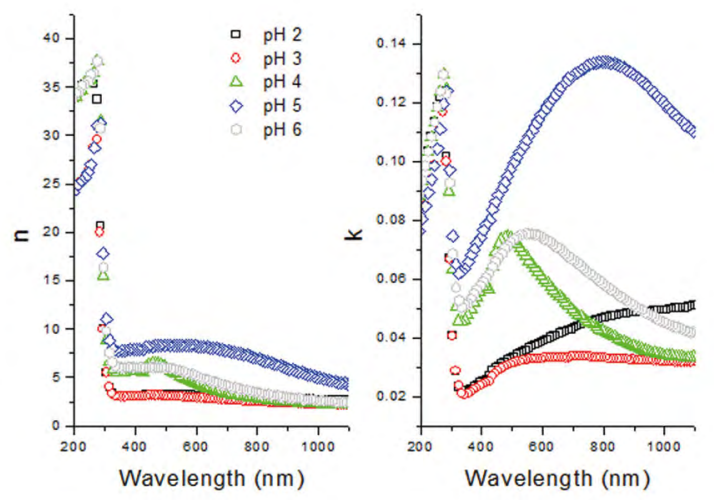

Figure 7. Refraction index (n) and extinction coefficient (k) of AgI thin films grown at different $\mathrm{pH}$ values.

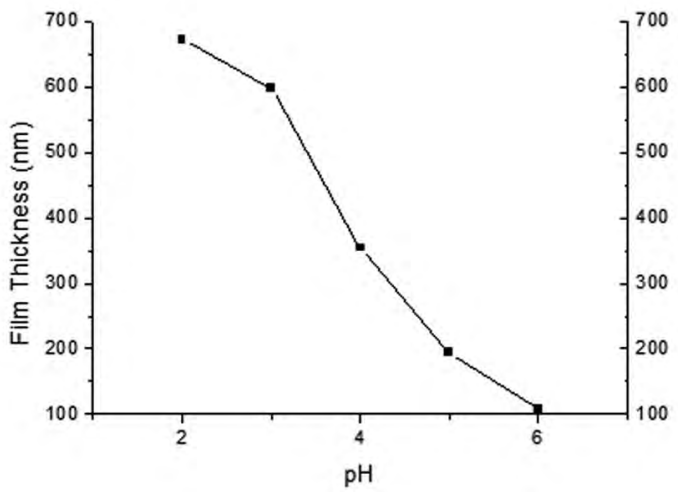

Figure 8. The film thickness changed with $\mathrm{pH}$ of the $\mathrm{AgI}$ thin films.

The real part or refraction index $\left(\mathrm{n}_{\mathrm{r}}\right)$ defines the phase velocity of light in material. The imaginary part or extinction coefficient $(\mathrm{k})$ determines attenuation into material. Thus, the optical constants represent the optical properties of a material in terms of electromagnetic propagation in the material. The values of dielectric constants versus the wavelength for the thin films are shown in Fig. 9. The dielectric coefficients of the crystals are changed to be $2.11,1.80,16.92,6.15$ and 7.63 at $\mathrm{pH}: 2-6$, respectively.

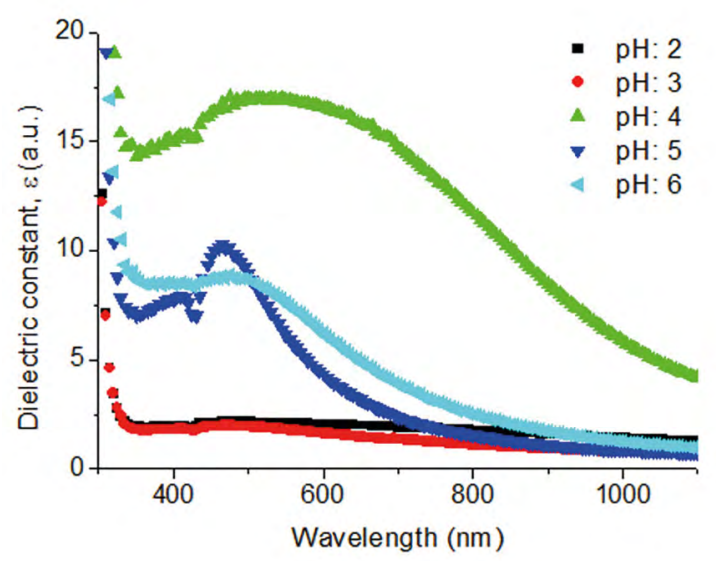

Figure 9. Dielectric coefficients $(\varepsilon)$ of AgI thin films grown at different $\mathrm{pH}$ values.

Light extinction and scattering by gold and silver nanoparticles by using Mie calculations and size-dependence of the extinction coefficient for silver and gold nanoparticles were given by Julien and Martinus ${ }^{32}$. They compared available experimental data concerning the molar extinction coefficients for gold and silver nanoparticles and the results obtained by Mie calculations and developed simple power-law definition for the dependence of the maximum extinction coefficient on particle diameter. Mie calculations have already been applied to obtain the extinction spectrum of gold nanoparticles in solution $^{33,34}$, but silver has received less attention. 
The experimental measurements of the extinction coefficients of silver nanoparticles for a range of sizes are obtained by Evanoff and Chumanov ${ }^{35}$. The agreements between the experimental data and the results obtained by Mie calculations are not very good. A quadrupole resonance was observed at short wavelengths for larger particle sizes (The spectral region of interest chosen was 320-420 nm), whose peak extinction coefficient is larger, but this band is neglected.

The optical response of silver is significantly affected by surface effects. It can be concluded that Mie calculations are actually most reliable method for silver nanoparticles, if these nanoparticles are mono-disperse and perfectly spherical. Also, the angular distribution of scattered light is of interest for the right-angle. Asymmetry parameter, which is the average value of the cosine of the scattering angle, can be estimated by the angular distribution of scattered light. The asymmetry parameter is zero for very small particles. Deviations from zero may be explained as changes in the angular distribution ${ }^{32}$. Also, high-index materials are used to make the filters and mirrors used in lasers with special reflecting by optimal designs, and these kind of structures based on heavy metal oxide have practical applications in the field of reflecting windows, glass ceramics, thermal and mechanical sensors, layers for optical and electronic devices, etc ${ }^{36}$.

\section{Conclusions}

AgI thin films have been grown on glass substrates by the CBD method at different $\mathrm{pH}$ values. XRD studies depict the phase transformation of AgI crystals. This effect can be explained by increasing of crystallite sizes and $\mathrm{pH}$ effect. SEM images show that increasing crystallite size and the grain structures turn into hexagonal from cubic when the $\mathrm{pH}$ values are increased. The results of EDX analysis depict the presence of Ag and I in the crystals. UV-VIS spectrophotometric analysis showed that the optical response of silver is much more sensitive to surface effects. According to optical properties, AgI thin films with high-index are appropriate to make the filters and mirrors used in lasers with special reflecting by optimal designs, layers for optical and electronic devices, reflecting windows and mechanical and thermal sensors.

\section{Acknowledgement}

This work was supported by the Karabük University Scientific Research Project Unit under Contract No: KBÜ-BAP-13/1-YL-033, KBÜ-BAP-14/2-DS-042 and KBÜ-BAP-16/1-YD-016. The authors would like to thank to the Karabük University Scientific Research Project Unit for their financial support.

\section{References}

1. Ovshinsky SR. Reversible Electrical Switching Phenomena in Disordered Structures. Physical Review Letters. 1968;21(20):14501452.

2. Suh DS, Lee E, Kim KHP, Noh JS, Shin WC, Kang YS, et al Nonvolatile switching characteristics of laser-ablated $\mathrm{Ge}_{2} \mathrm{Sb}_{2} \mathrm{Te}_{5}$ nanoparticles for phase-change memory applications. Applied Physics Letters. 2007;90(2):023101.

3. Otterwill RH, Woodbridge RF. The preparation of monodisperse silver bromide and silver iodide sols. Journal of Colloid Science. 1961;16(6):581-594.

4. Berry CR. Structure and Optical Absorption of AgI Microcrystals. Physical Review. 1967;161(3):848.

5. Tanaka T, Iwasaki M. The multistage process of formation of ultrafarine silver bromide particles as revealed by multichannel spectrophotometry. J. Imaging Sci. 1985;29(3):86-92.

6. Hayes D, Schmidt KH, Miesel D. Growth mechanisms of silver halide clusters from the molecule to the colloidal particle. The Journal of Physical Chemistry. 1989;93(16):6100-6109.

7. Mulvaney P. Nucleation and stabilization of quantized AgI clusters in aqueous solution. Colloids and Surfaces A: Physicochemical and Engineering Aspects. 1993;81:231-238.

8. Vucemilovic MI, Micic OI. Electron-transfer reactions of extremely small AgI colloids. International Journal of Radiation Applications and Instrumentation. Part C. Radiation Physics and Chemistry. 1988;32(1):79-83.

9. Micic OI, Nenadovic MT, Rajh T, Nedeljkovic JM, Vucemilovic MI. Kinetic and spectroscopic properties of small colloids of metal iodide semiconductors. In: Degiorgio V, ed. Progress in Colloid and Polymer Science, Volume 76 - Trends in Colloid and Interface Science II. New York: Springer; 1988. p. 20-23.

10. Schmidt KH, Patel R, Meisel D. Growth of silver halides from the molecule to the crystal. A pulse radiolysis study. Journal of the American Chemical Society. 1988;110(15):4882-4884.

11. Henglein A, Gutiérrez M, Weller H, Fojtik A, Jirkovský J. Photochemistry of colloidal semiconductors 30. Reactions and fluorescence of $\mathrm{AgI}$ and $\mathrm{AgI}-\mathrm{Ag}_{2} \mathrm{~S}$ colloids. Berichte der Bunsengesellschaft für physikalische Chemie. 1989;93(5):593600

12. Mićić OI, Meglić M, Lawless D, Sharma DK, Serpone N. Semiconductor photophysics. 5. Charge carrier trapping in ultrasmall silver iodide particles and kinetics of formation of silver atom clusters. Langmuir. 1990;6(2):487-492.

13. Chen SH, Ida T, Klimura K. Thiol-Derivatized AgI Nanoparticles:? Synthesis, Characterization, and Optical Properties. The Journal of Physical Chemistry B. 1998;102(32):6169-6176.

14. Brelle MC, Zhang JZ. Femtosecond study of photo-induced electron dynamics in $\mathrm{AgI}$ and core/shell structured $\mathrm{AgI} / \mathrm{Ag} 2 \mathrm{~S}$ and $\mathrm{AgBr} / \mathrm{Ag} 2 \mathrm{~S}$ colloidal nanoparticles. The Journal of Chemical Physics. 1998;108(8):3119.

15. Ida T, Kimura K. Ionic conductivity of small-grain polycrystals of silver iodide. Solid State Ionics. 1998;107(3-4):313-318. 
16. Wang Y, Mo J, Cai W, Yao L, Zhang L. Synthesis of nanoAgI arrays and their optical properties. Journal of Materials Research. 2001;16(4):990-992.

17. Kennedy JH. Thin film solid electrolyte systems. Thin Solid Films. 1977;43(1-2):41-92.

18. Ves S, Glötzel D, Cardona M, Overhof H. Pressure dependence of the optical properties and the band structure of the copper and silver halides. Physical Review B. 1981;24(6):3073-3085.

19. Goswami A. Thin Film Fundamentals. $1^{\text {st }}$ ed. New Delhi: New Age International; 1996. p. 51-71.

20. Liang XF, Chen Y, Shi L, Lin J, Yin J, Liu ZG. Resistive switching and memory effects of AgI thin film. Journal of Physics D: Applied Physics. 2007;40(16):4767-4770.

21. Kumar PS, Dayal PB, Sunandana CS. On the formation mechanism of $\gamma$-AgI thin films. Thin Solid Films. 1999;357(2):111-118.

22. Validzic IL, Jokanpvic V, Uskokovic DP, Nedeljkovic JM. Influence of solvent on the structural and morphological properties of AgI particles prepared using ultrasonic spray pyrolysis. Materials Chemistry and Physics. 2008;107(1):28-32.

23. Mamazza R Jr., Morel DL, Ferekides CS. Transparent conducting oxide thin films of $\mathrm{Cd}_{2} \mathrm{SnO}_{4}$ prepared by RF magnetron cosputtering of the constituent binary oxides. Thin Solid Films. 2005;484(1-2):26-33.

24. Ferro R, Rodríguez JA, Vigil O, Morales-Acevedo A. Chemical composition and electrical conduction mechanism for CdO:F thin films deposited by spray pyrolysis. Materials Science and Engineering: B. 2001;87(1):83-86.

25. Callister WD. Materials Science and Engineering: An Introduction. Hoboken: John Wiley and Sons; 1997. p. 102.

26. Pejova B, Grozdanov I, Tanuševski A. Optical and thermal band gap energy of chemically deposited bismuth(III) selenide thin films. Materials Chemistry and Physics. 2004;83(2-3):245-249.
27. Benramdane N, Murad WA, Misho RH, Ziane M, Kebbab Z. A chemical method for the preparation of thin films of $\mathrm{CdO}$ and ZnO. Materials Chemistry and Physics. 1997;48(2):119-123.

28. Kondo S, Itoh T, Saito T. Strongly enhanced optical absorption in quench-deposited amorphous AgI films. Physical Review $B$. 1998;57(20):13235-13240.

29. Cardona M. Optical Properties of the Silver and Cuprous Halides. Physical Review. 1963;129(1):69-78.

30. Meydaneri Tezel F, Kariper IA. Synthesis, surface tension, optical and dielectric properties of bismuth oxide thin film. Materials Science-Poland. 2017;35(1):87-93.

31. Meydaneri Tezel F, Özdemir O, Kariper IA. The effects of $\mathrm{pH}$ on structural and optical characterization of iron oxide thin films. Surface Review and Letters. 2017;24(4):1750051. DOI: $10.1142 / \mathrm{S} 0218625 \mathrm{X} 17500512$

32. Navarro JRG, Werts MHV. Resonant light scattering spectroscopy of gold, silver and gold-silver alloy nanoparticles and optical detection in microfluidic channels. Analist. 2013;138(2):583592

33. Haiss W, Thanh NTK, Aveyard J, Fernig DG. Determination of Size and Concentration of Gold Nanoparticles from UV-Vis Spectra. Analytical Chemistry. 2007;79(11):4215-4221.

34. Khlebtsov NG. Determination of Size and Concentration of Gold Nanoparticles from Extinction Spectra. Analytical Chemistry. 2008;80(17):6620-6625.

35. Evanoff DD, Chumanov G. Size-Controlled Synthesis of Nanoparticles. 2. Measurement of Extinction, Scattering, and Absorption Cross Sections. The Journal of Physical Chemistry B. 2004;108(37):13957-13962.

36. Konijnendijk WL, Stevels J. The structure of borosilicate glasses studied by Raman scattering. Journal of Non-Crystalline Solids. 1976;20(2):193-224. 